SAND79-0645

Unlimited Release

UC. 25,28

\title{
Metal Tritides Helium Emission
}

\author{
Leomard C. Beavis
}

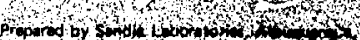

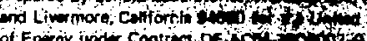

rinted Februery 1900 


\title{
MASTER
}

UC25-UC28

\author{
SAND79-0645 \\ Uni imited Release \\ Printed February 1980
}

METAL TRITIDES HELIUM EMISSION

\author{
Leonard $C$. Beavis \\ Tube Development Division 2354 \\ Sandia Lahoratories, Albuquerque, N.M. 87185
}

\begin{abstract}
Over the past several years, we have been measuring the release of heliun from metal tritides (primarily erbium tritide). He find that qualitatively all tritides of interest to us behave the same. When they are first forned, the helium is released at a law rate that appears to be related to the aniount of surface area which has access to the outside of the material (either film or bulk). For example, erbium tritide films initially release about $0.3^{\text {tr }}$ of the helium generated. Most tritide films enlit helium at about this rate initially. At some later time, which depends upon the amount of helium generated, the parent occluding element and the degree of tritium saturation of the dihydride phase the helium emission changes to a new mode in which it is released at approximately the rate at which it is generated (for example, we measure this value to be =.31 He/Er for ErT1.9 films). If erbium ditritide is saturated beyond $1.9 \mathrm{~T} / \mathrm{Er}$, the critical helium/metal ratio decreases. For example, in bulk powders $\mathrm{ErT}_{2.15}$ reaches critical release concentration at $=0.03$. Moderate elevation of temperature above room temperature has little impact on the helium release rate, It appears that the process may have $=2 \mathrm{kcal} /$ mol activation energy. The first lielium formed is well bound. As the tritide ages, the helium is found in higher energy sites. Similar but less extensive measurenents on scandium, titanfum, and zirconium tritides are also described. Finally, the thermal desorption of erbium tritides of various anes from 00 days to 3154 days is discussed. Significant helium is desorbed along with trie tritium in all but the youngest samples during thermodesorption.
\end{abstract}

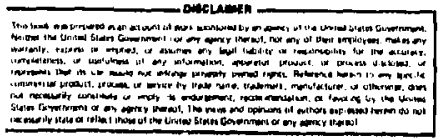




\section{PREFACE}

This report is a summary of the helium release measurements on approximately 50 samples. These are all of the samples for which we have been making measurements over the past five years except those reported in Reference 1. Some of the samples are currently being measured. For other samples, measurements have terminated. Dean J. Mitcheil, 2353, SL.A, is presentiy continuing measurements on the tritides. He has refined the measurement schnique to reduce the mass-3 signal interference by hydrogen isotopes. The major impact of this refinement has been to reduce the scatter in data or the eariy release fraction (RFI) and reduce the average early RFI to about $1 \times 10^{-3}$ fiom erbium tritide films.

\section{ACKNOWLEDGMENT}

I would like to thank J. L. Provo and W, C. Brown, Beneral Electric Company, St. Petersburg, Florida, for their assistance as preparers of all of the tritide samples reported upon in this document. Thanks are also due to $\mathrm{W}$. G. Perkins for his support and encouragement on these studies and to W. J. Kass for developing most of the software used for data collecting and for supervising early measurement of many of the samples. Finally, I thank B. G. Self, D. R. Begeal, and R. C, Patrick for bullding and maintaining the measurement apparatus and for taking most of the data over the past several years. 


\section{INTRODUCTION}

The fusion of tritium and deuterium ${ }^{2}$ to produce neutrons has many important technological applications. ${ }^{3,4}$ We are particularly interested in conpact neutron generators. In order to increase the hydrogen isotope density, thus reducing the size of the neutron producing target, tritium or deuterium is commonly combined chemicaliy with a metal. Metals in the periodic table, groups 111 and IV transition elements as well as the lanthanides and actinides, are particularly useful because they form thernally stable hydrides which display hydrogen densitles equal to or greater than that of solid hydrogen. 5

Tritium decays with a half life of 12.3 years. The decay products are an electron, neutrino, and ${ }^{3}$ He ion. The recoil energy of the helium $(1.03 \mathrm{eV}$ average $)$ is so low that it will not move an appreciable distance from its point of generation in a metal tritide. It is well known ${ }^{3}, 6-13$ that at least initialiy most of the hel ium generated is retained by the solid tritide ( $>99 \%$ ). Although most of the helium is retained at first, at some concentration, which is material and tritium concentration dependent, the helium is released at approximtely its generation rate from the tritide. Much effort ${ }^{14-18}$ has been devoted to explaining why helium is retained at low levels and then at some critical concentration $(.02-.35)$ it is no longer retained. This report will deal with the data obtained from simples in the early (low helium concentration) release stage. The samples discussed include those at room temperature of titanium. 2irconiun, scandium, and erbium tritides. Results of the stoichionetry effect masurements on erbiun tritide films (Ref. 1 described bulk samples only) are included. In addition, details of the effects of the grain size, storage temperature, and themal raw on hellum emissions from erbium tritide films will be given. Finally, measurements of the melium release from single crystal scandium-0.4 tritiun will be described.

\section{EXPERTMENTAL}

The experimental techniques used to masure the steady flow of heliua from the samples is described in Ref. 1. The vacuun system has been changed, F1gure 1, to accomodate 39 samples plus the' stendard for calibration. The thermally ramped samples were masured as described in Rof. 19. All data from elthar type of expariment are 


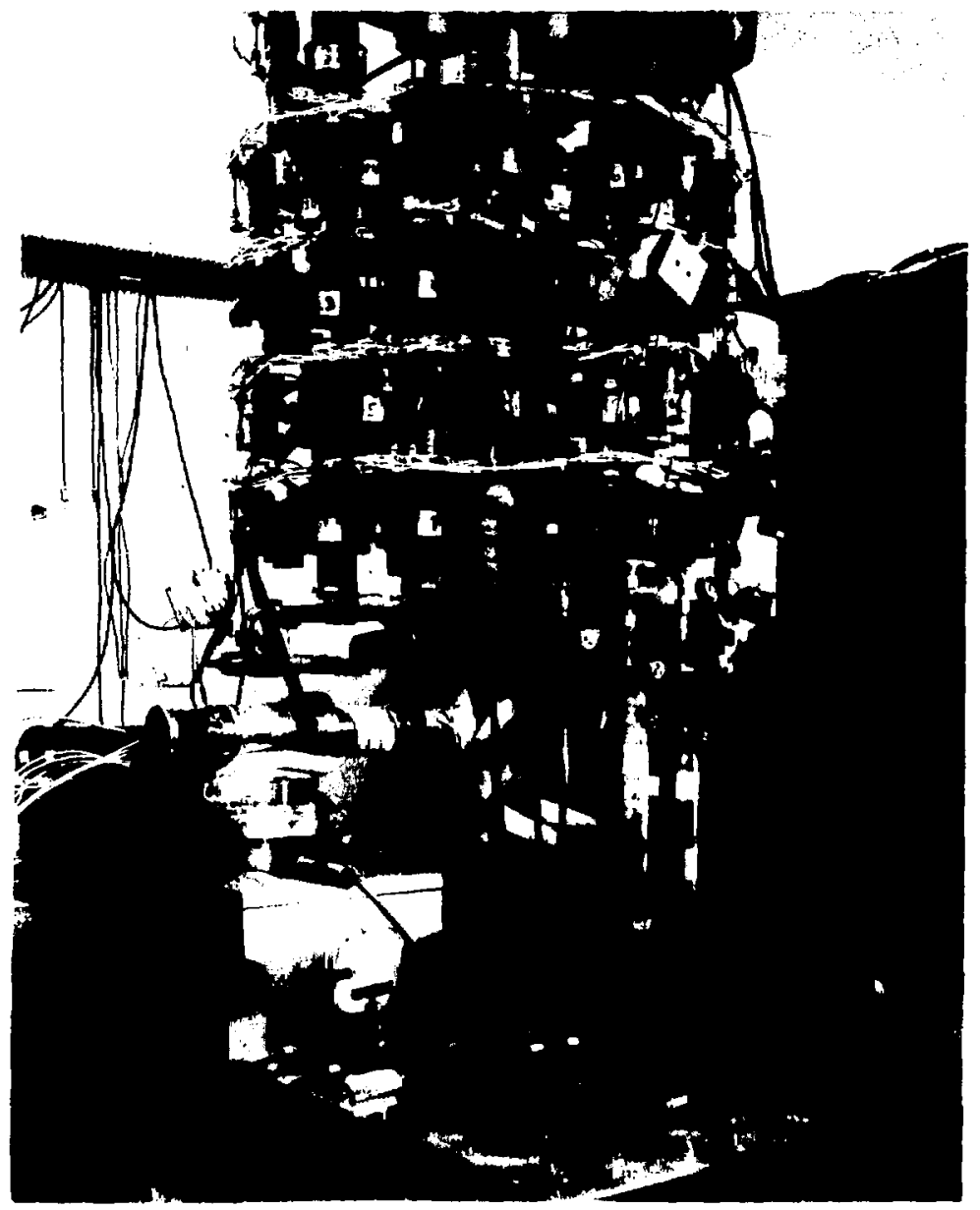

Figure 1. Phatograph of the dyitamic ज़He release measurement apparatus. 
taken and stored under computer control. The gases evolved are measured with a quadrupole analyzer by mass number. All of the samples described were prepared at General Electric Company, St. Petersburg, Florida, under the supervision of J. L. Provo.

\section{RESULTS}

The data given in the follawing five sections are plots of RFI versus helium-tometal ratio. RFI is the instantaneous release fraction, i.e., the number of helium atoms emitted per second divided by the number of helium atoms generated per second at the time the measurement was made. It should be noted that a constant, with time, absolute emission rate would appear as a continually increasing RFI because the helium generation rate decreases with age (time). The helium-to-metal ratio is the number of helium atoms generated per metal atom. As long as RFI is quite smal7, the number of helium atoms retained by the lattice/metal atom is equal to the helium-to-metal ratio. As RFI increases, the actual helium retained by the lattice is found by subtracting the integral of RFI from the helium-to-metal ratio. Because of tile nature of the rapid release phenomenon, it is probably satisfactory to fix the maximum and old age helium retained/metal ratio at the value $i t$ had at the onset of rapid release of helium.

a. Tritide of various metals--room temperature.

The hellum emission from three erbium tritide films all produced at the same time and with the same atomic ratio $(1.9)$ of tritium to metal is displayed in Figures 2, 3, and 4. The sample, whose data are seen in Figure 2, was exposed

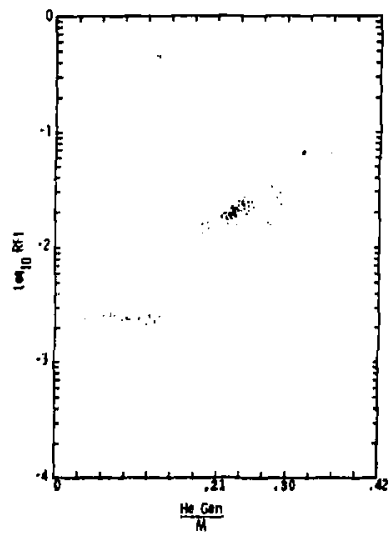

Fig. 2

Instantaneous release fraction (RFI) vs. hellum generated-to-metal ratio (He/M) for erbium tritide for initial atomfc ratio $\left(A . R_{1}\right)=1.9$. Sample with uncontrolled air exposure at mid life. No air exposure from film deposition to tritiding. 


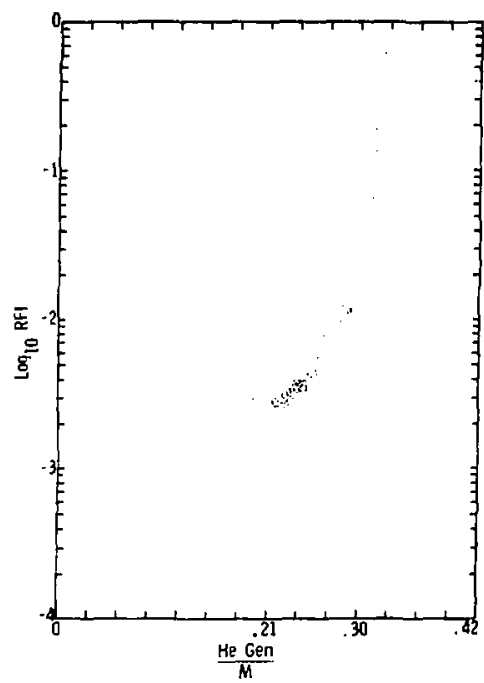

Fig. 3. RFI versus He/M for erbium tritide film A,R. 1.9 with no air exposure from $f i l m$ deposition to tritiding and minima? air exposure thereafter.

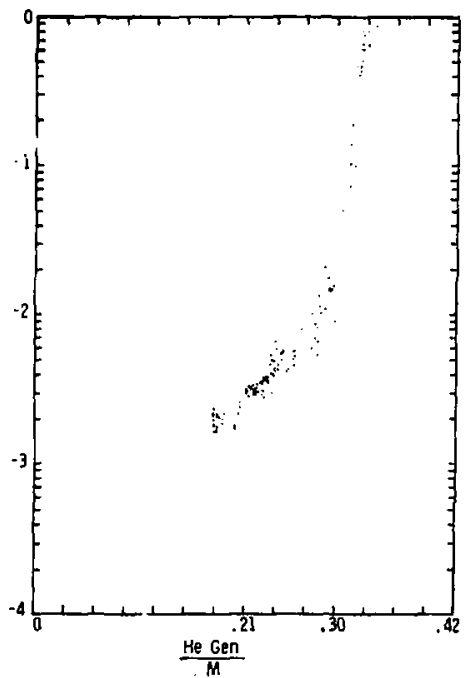

Fig. 4, Sister to sample 3.

to air for a few weeks at a He/M ratio of $\approx .15$ while the vacuum equipment was being enlarged to handle more samples. The other two samples saw only a few minutes air exposure. They had been stored in vacuua, but not measured, from the time they were formed until they were placed on the measurement apparatus at $\mathrm{Hr} / \mathrm{H} \approx 0.15$. It is clear that the alr exposure had a profound effect on the rhe outgassing in the sample which was exposed in a more or less uncontrolled fashion. The two samples which turned on abruptly (RFI $>0.1$ ), Figures 3 and 4 , did so identically at $\mathrm{He} / \mathrm{H}$ ratio of $\approx 0.3$, which is not much different from the value reported in Ref. 13. Figures 5 through 8 dlsplay the ${ }^{3}$ He desorption from samples of erbium tritido film which had the same inftial tritium-to-metal ratio as those fron Figures 2, 3, and 4 . They were produced four years later than the samples in Figures 2, 3, and 4, under somewhat different processes. The early ${ }^{3}$ He release characteristics do not seem to be much different (RFI a 

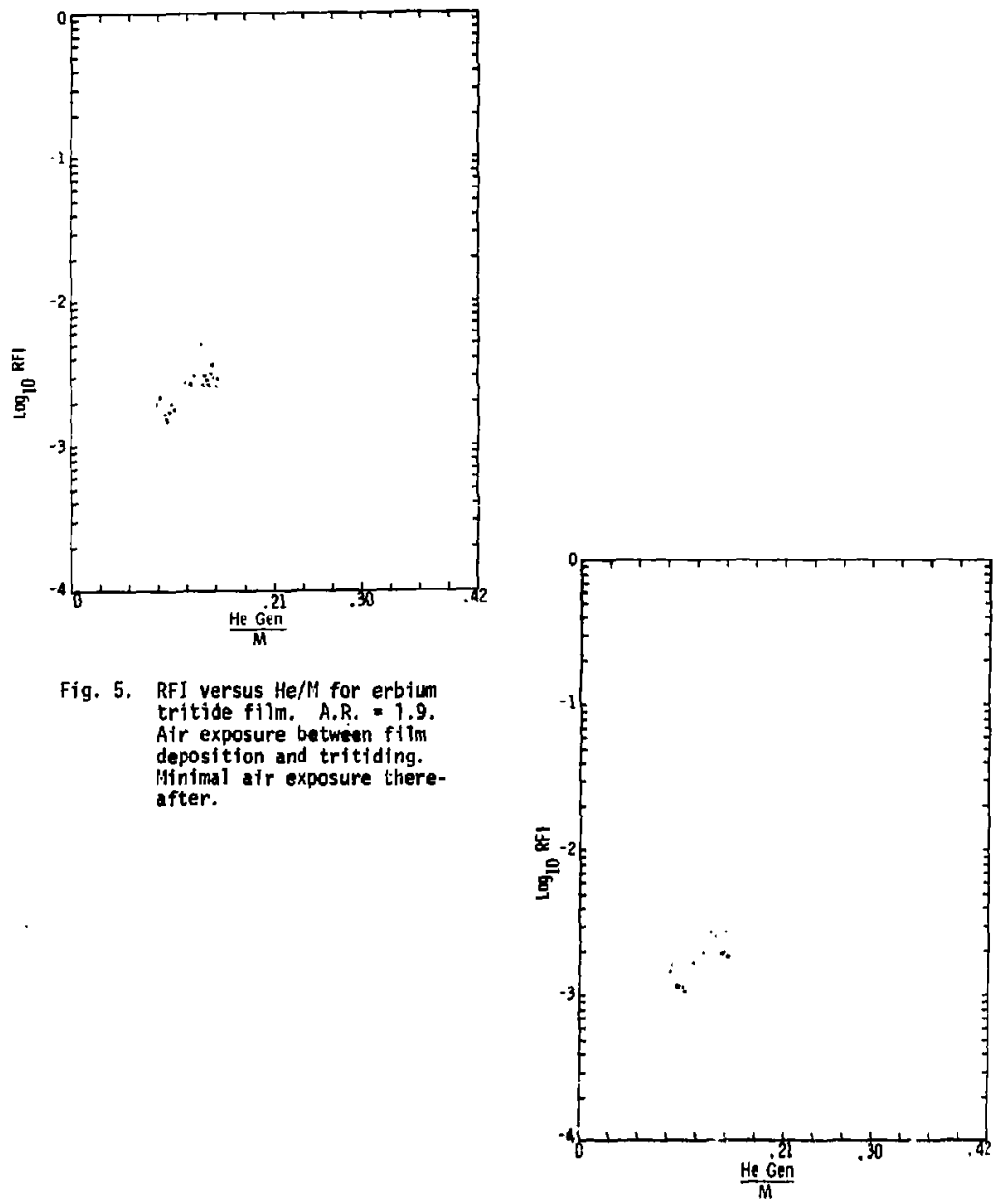

Fig. 5. RFI versus $\mathrm{He} / \mathrm{M}$ for erbium tritide film, A.R. $=1.9$. Air exposure between film deposition and tritiding. Minimal air exposure thereafter.

fig. 6. Stmilar to film in Fig. 5. Produced at a different time. 


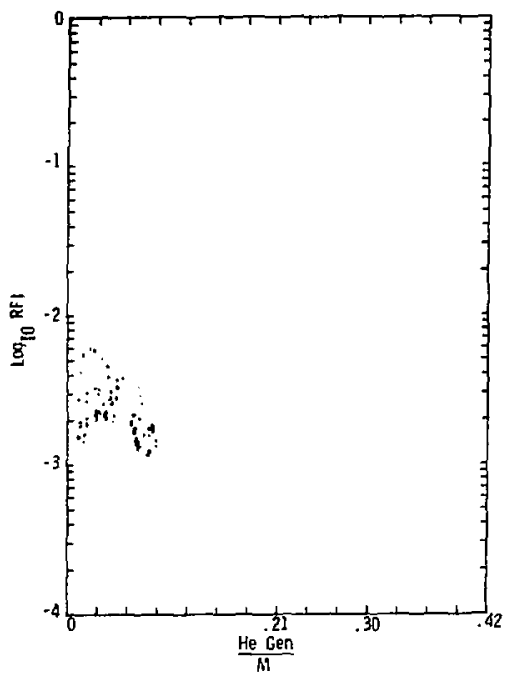

Fig. 7. Simitar to film in Fig. 5. Produced at a different time.

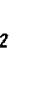

$-1$

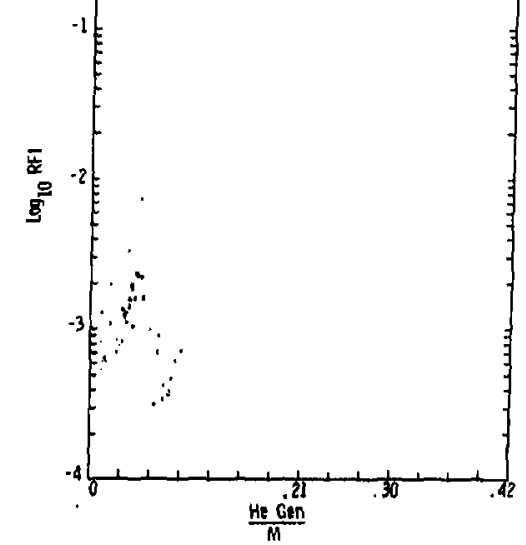

Fig. 8. Similar to film in Fig. 5. Produced at differant time. 
few tenth of a percent) from the earlier films. Figure 9 portrays a sample which has an initial RFI of $\approx 0.01$; its initial tritium-to-metal ratio was 1.8 . Although the release fraction is somewhat high, it is probably not out of the range one would expect to see. In all other respects, it appears normal. Figure 10 is the ${ }^{3} \mathrm{He}$ outgassing from an old erbium-tritide sample. It is contained in a glass bulb with a break seal by which it was attached to the vacuum system. It displays the high flow of ${ }^{3} \mathrm{He}$ expected now from an erbium-tritide sample produced in 1972 .

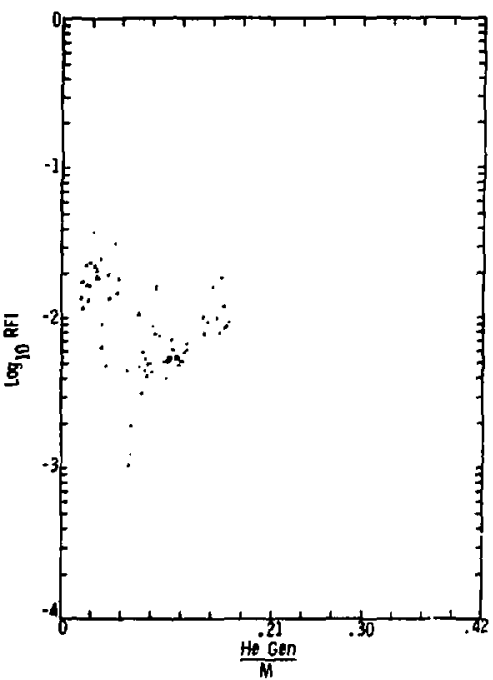

F1g. 9. RFI versus $\mathrm{He} / \mathrm{M}$ for erbium tritide film. A.R. = 1.8. Produced itke the flims in Figs. 5-8. Note the high RFI.

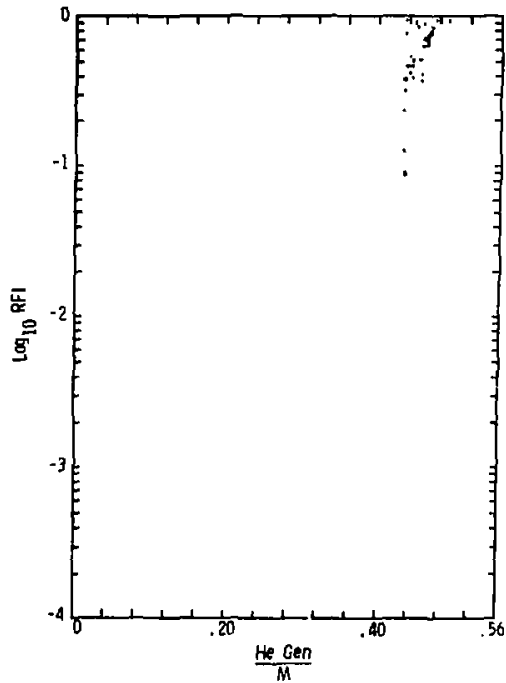

Fig. 10. RFI versus He/M erbium tritide film. A.R. = 1.9, old sample.

The next three :figures 11,12 , and 13) display the ${ }^{3}$ He emission from three scandium tritide samples. Scandium is the one transition element which is known to dissolve considerable hydrogen in the metal phase (Ref. 5), 1.e., 40\% atomic percent at room temperature without forming the hydride. Figures 11 and 12 are of $\mathrm{ScT}_{1.9}$ films, and Figure 13 is of ScT0.2. Scandtum tritide goes ințo its rapid release mode at a low helium-to-metal ratlo. In fact, from most of the data seen here, it is not clear that these materiais hove any initial stabie low 3 He emission stage. 


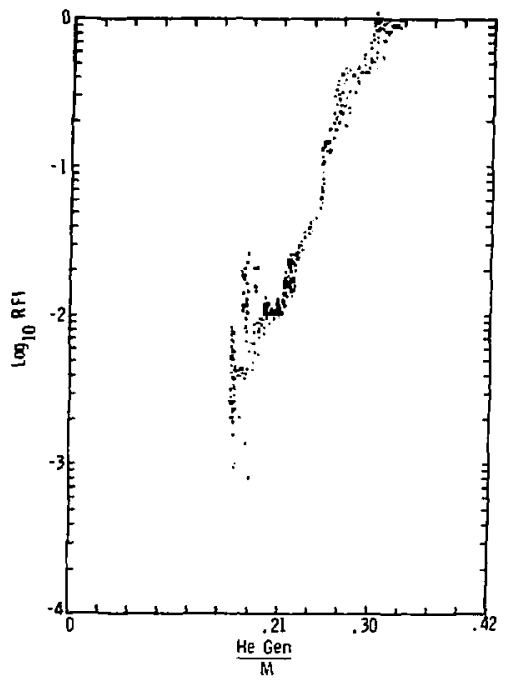

Fig. 11. RFI versus $H e / M$ for scandium tritide film. A.R. $=1.9$.

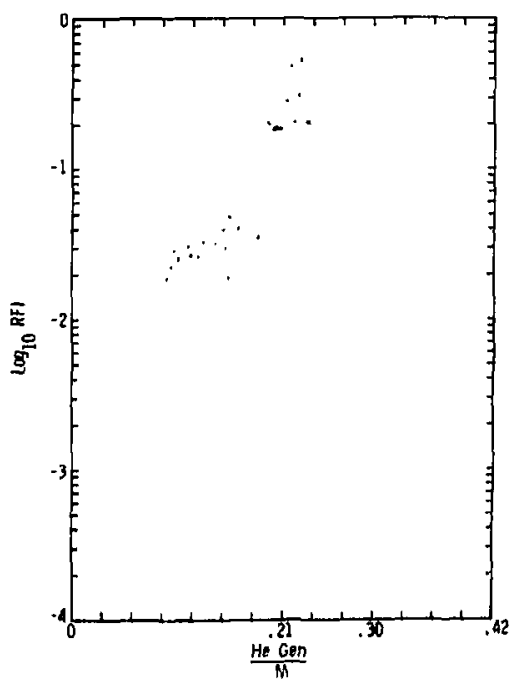

F1g. 12. RFI versus He/M for scandium trittde fllm. A,R. 1.9 . 


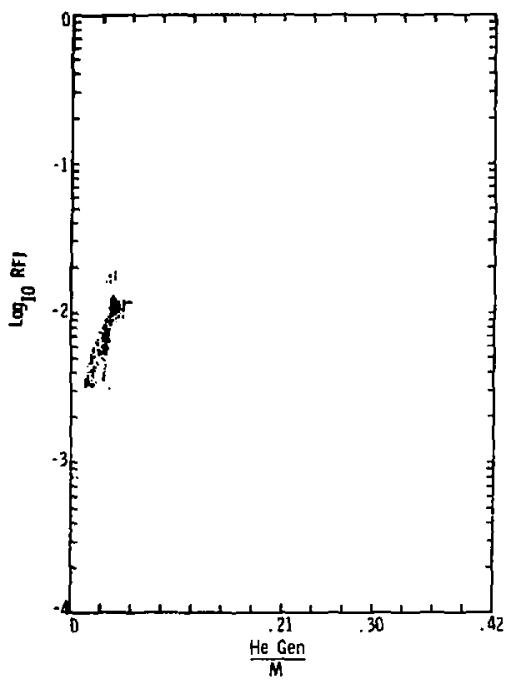

Fig. 13. RFI versus $\mathrm{He} / \mathrm{M}$ for scandium tritide ftlm. A.R. $=0.2$.

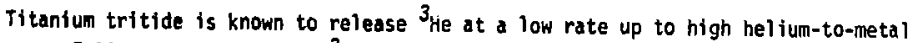
ratio. 7,13 Figure 14 is the $3_{\text {He output from }} \pi 1 T_{1.9} \mathrm{fllm}$. Note that the helium-tometal ratio for the onset of rapid release is about 0.4 . This is higher than the values measured eartier. ${ }^{13}$ The reason for this discrepancy is not known. Sister samples were analyzed for initial tritlum-to-metal ratio and confimed the atomic ratio.

Figure 15 is a plot of the ${ }^{3}$ He emission fram $2 r T_{1.5}$. It appears that zirconium tritide retains 1 ts internally generated ${ }^{3}$ He to a very high helium-to-metal ratio. 


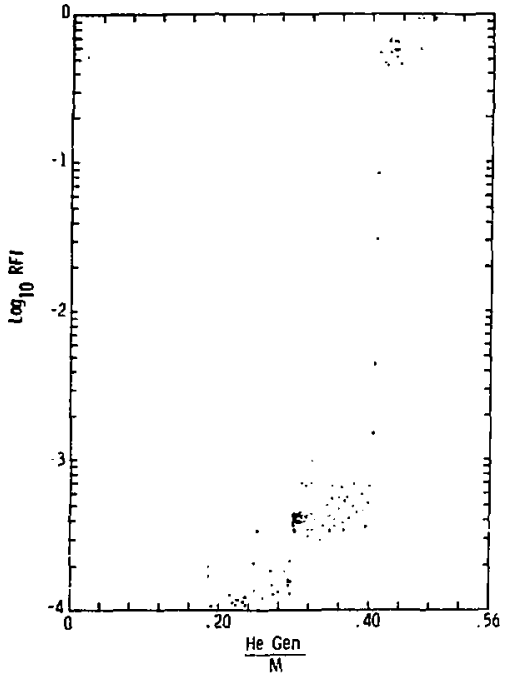

Fig. 14. RFI versus $\mathrm{He} / \mathrm{M}$ for titanium tritide film. A.R. $=1.9$.

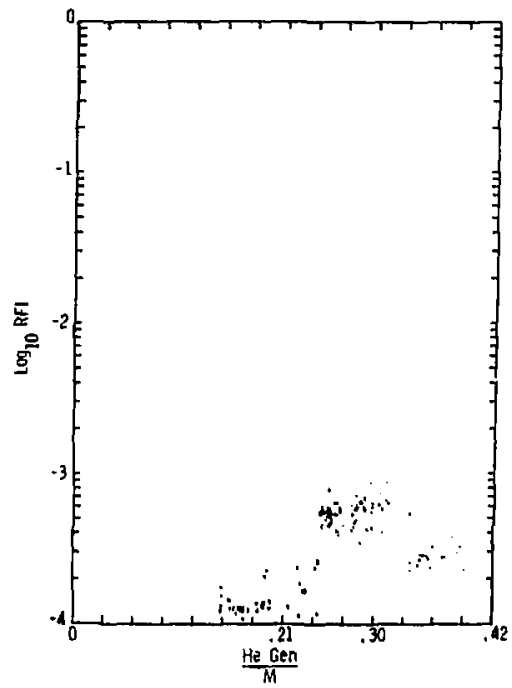

Ftg. 15. RFI versus $H e / M$ for zircontum tritide fllm. A.R. $=1,5$ 
b. Influence of Grain Size on ${ }^{3} \mathrm{He}$ Emisston

It was apparent early in these measurements that the early ${ }^{3}$ He release from erbfumtritide films was greater than that from the bulk samples prepared with the same initial atomic ratio. For example, note that the initial flow (RFI) from films is typically $2-3 \times 10^{-3}$, see Flgures $2-6$, whereas the initial RFI from bulk samples of tritium-to-metal atomic ratio 2.0 is an order lower, figure 16.

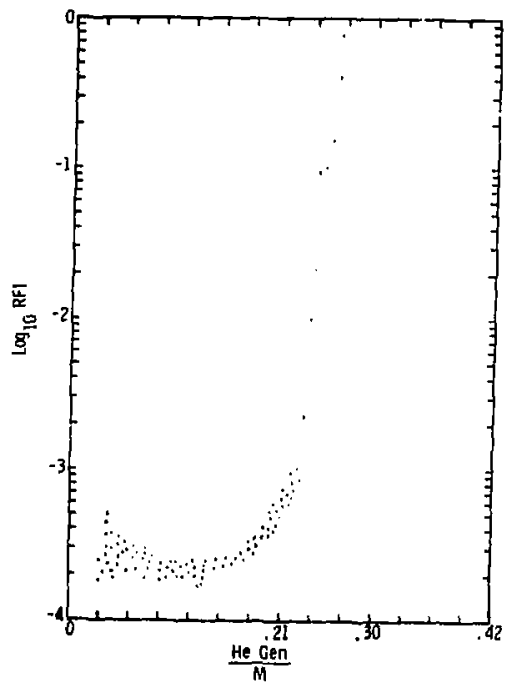

Fig. 16. RFI versus He/M for erblum tritide powder. A.R. $=2.0$.

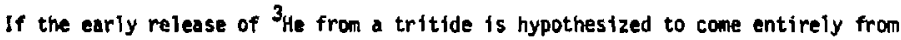
grain boundary decay of trittum, then it should be possible to predict the release fraction if the gratn size can be measured. Assumed is the easy access to any external surface by hallum genorated on an internal grain boundary. The predicted release fraction from a simple structure of cublc grains 15 given in Figure 17.

3. L. Provo, GEND, furnishad transmission electron micrographs of erbium-tritide (A,R. - 1.9) films from which we whe to make grain size measurements. The bulk tritide grain size was measured from S.E.M. photos. The resolution of the 


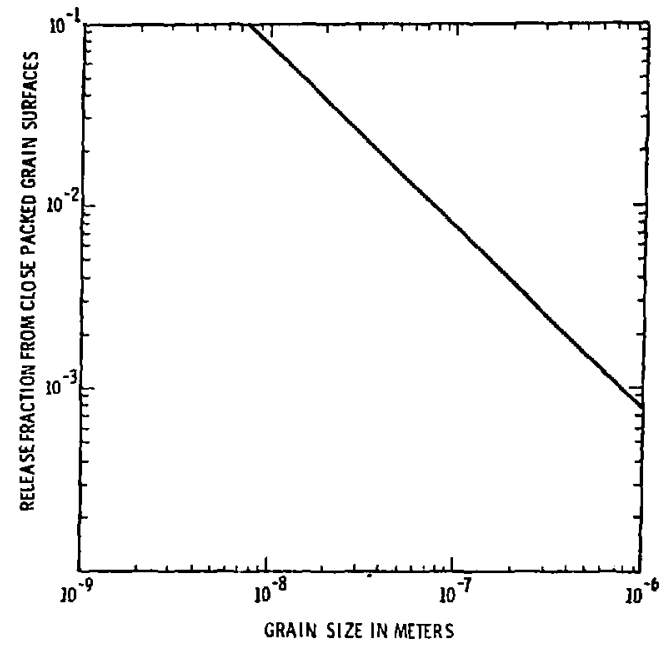

Fig. 17. RFI versus size for cubes of tritide, A.R. $=2.0$.

S.E.M. was about $300 \AA$. The measured distribution of grain sizes for tre film and bulk is given in Figure 18. Table I below compares the predicted and measured values for RFI for the two largely different grain sized erbium tritides.

Table I

\begin{tabular}{|cccc|}
\hline Samples & $\begin{array}{c}\text { Average } \\
\text { Grain Size }\end{array}$ & Predicted RFI* & Measured RFI \\
ErT $_{1.9}(f i 1 \mathrm{~m})$ & $.13 \mathrm{um}$ & $9 \times 10^{-3}$ & $2-3 \times 10^{-3}$ \\
ErT $_{2.0}$ (bulk) & $3.0 \mathrm{um}$ & $3.8 \times 10^{-4}$ & $2.5 \times 10^{-4}$ \\
\hline
\end{tabular}

* Based on distribution of grain sizes, not average grain size. 


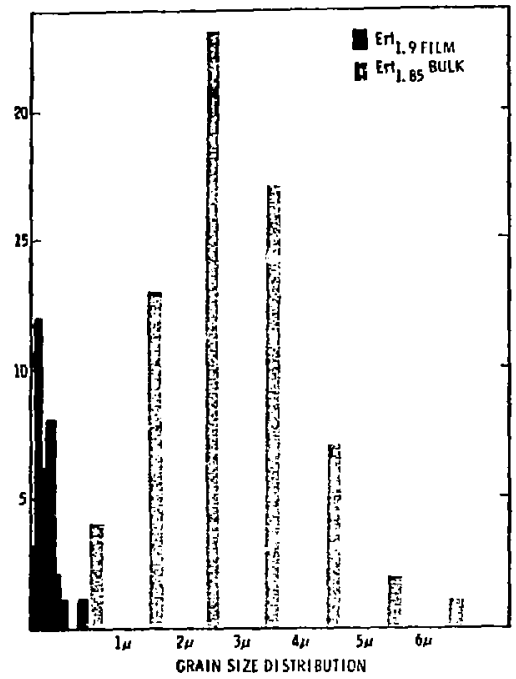

Fig. 18. Dis'ribution of measured grain sizes for erbium tritide bulk and film.

Most of the rare earth and transition metal liydrides cannat be formed in large single crystals. It would be desirable to test the grain boundary emission hypothesis on large single crystals. As pointed out earlier. scandium metal (HCP) will dissolve up to 40 atomic percent without changing phase. Therefore, two large ( $\approx 7 \mathrm{~mm}$ dia. $\times 2 \mathrm{~mm}$ thick) single crystals of scandium were tritided to a . $35 \mathrm{~T} / \mathrm{Sc}$ (by Provo at GEND). These were measured to ascertain that they remained single crystals after tritiding. Figures 19 and 20 are the plots of HFI versus helium-to-netal ratio for the two crystalligraphically differently oriented single crystals. 


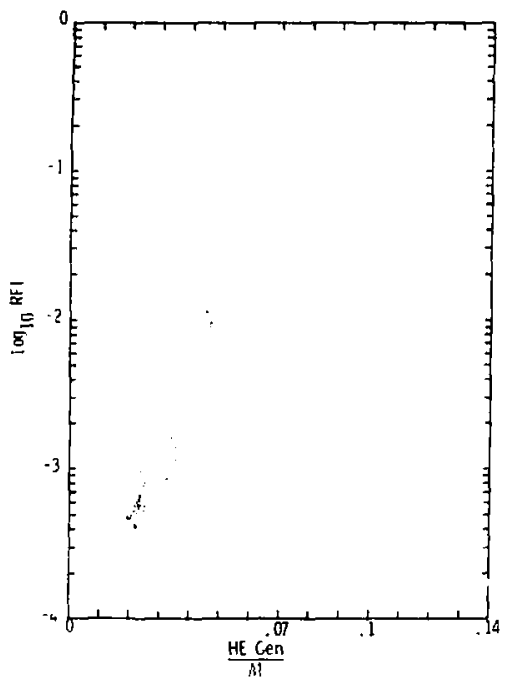

Fig. 19. RFI versus $\mathrm{He} / \mathrm{M}$ for scandium tritide single crystai. A.R. $=.35$, orientation of faces - 1120 .

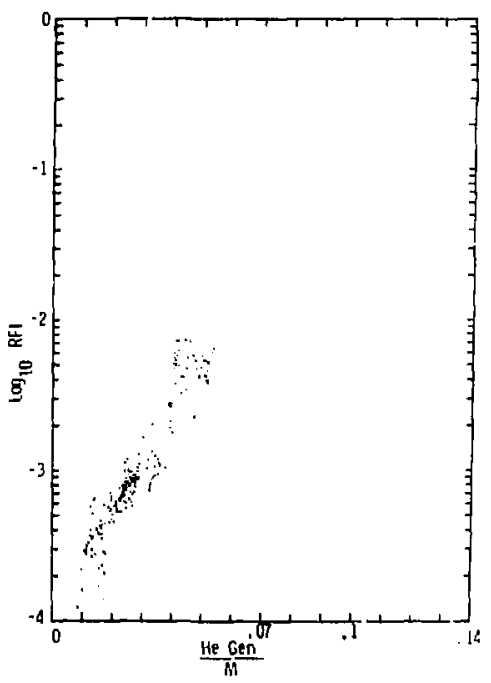

Fig. 20. RCI versus $\mathrm{He} / \mathrm{M}$ for scandium tritide single crystal. A. K. - . 35 , orientation of faces - 000l. 
c. Stoichiometry Effect in Films

In Reference 1, the effects of saturation of the ditritide phase of erbium were reported. A reproduction of that data on the onset of rapid release is give in Table 11 .

Table II

\begin{tabular}{|ll|}
\hline A.R. & He/M at onset of rapid release (RFI >0.01) \\
1.85 & .221 \\
1.95 & .200 \\
2.06 & .147 \\
2.11 & .048 \\
2.15 & .030
\end{tabular}

Films have been produced to determine if the same concentration effect is noted in them. Figures 2-4 show that the rapid release onset occurs at $\mathrm{He} / \mathrm{M}$ of $0.28^{*}$ for samples with tritium $T / E r$ ratio of 1.9. Figures 21 and 22 are data from films with initial isotope to erblum ratios of 2.0 , while Figure 23 is data from a film with an initial ratio of 2.13. Table III is a sumary of data from these samples.

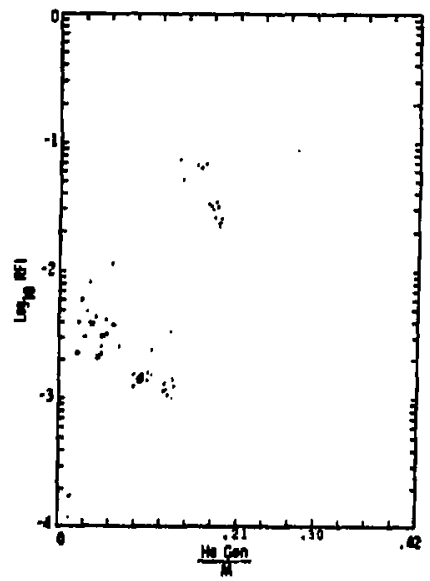

Fig, 21. RFI versus He/M for erbium tritide film. A.R. $=2,0$.

- Criteria for comparison set' at RFI $=0.01$. 


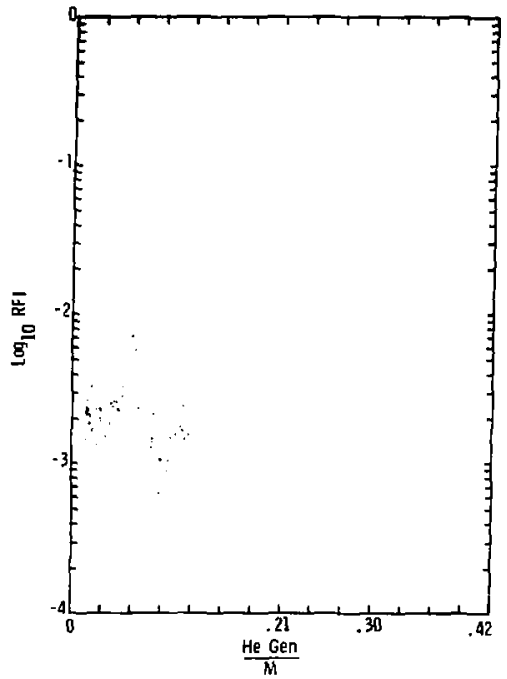

Fig. 22. RFI versus He/M for erblum tritide film. A.R. $=2.0$.

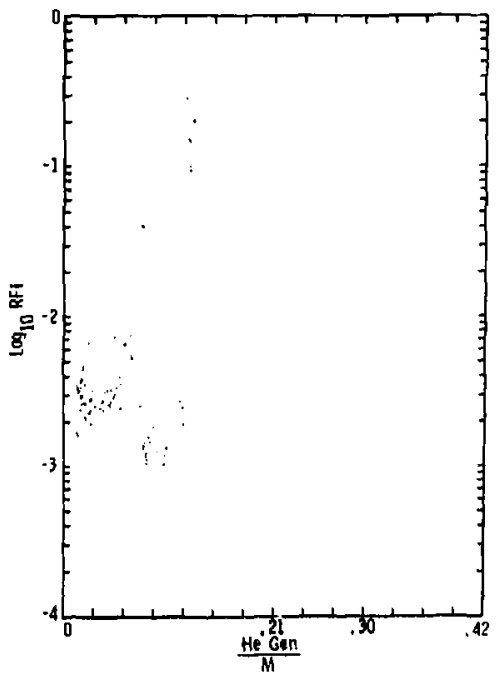

Fig. 23. RFI varsus Ho/M for arblum tritide film, A.R. $=2.13$ 
Table III

\begin{tabular}{lr|} 
A.R. & He/M at onset of rapid release (RFI >0.01) \\
1.9 & $0.2 B$ \\
2.0 & 0.16 \\
2.13 & 0.12
\end{tabular} \mid All films $=5$ um thick.

The trend is similar to that noted earlier for bulk samples. The onset values are generally larger for films. One erbium tritide sample which had an initial atomic ratio of 2.2 was subsequently baked at $500^{\circ} \mathrm{C}$ for one hour to reduce the A.R. to a value below 2.0. This was done in order to determine if a film which was intially over tritided would retain any "memory" of the over tritiding and thus reach the onset of rapid helium release earlier than a film of the same tritium-to-metal ratio which had never been in the super-stoichiometric state. Figure 24 shows the data from this sample. It appeurs that to this point the high initial tritium-to-metal ratio has had no ill effect. In fact, when it was initially placed an the measurement apparatus, the RFI was too low to measure.

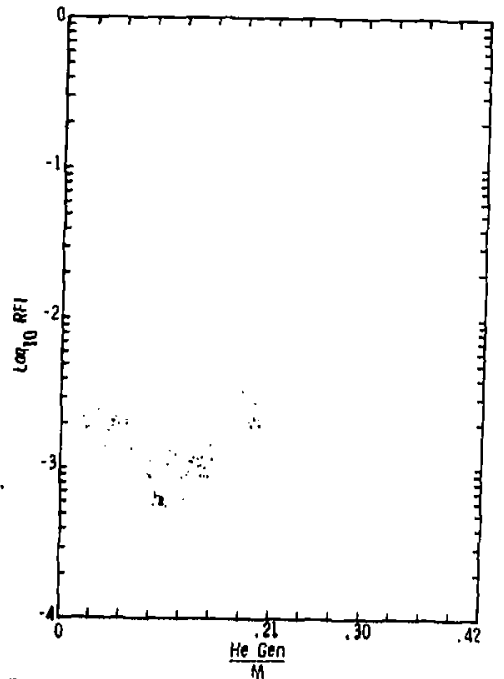

Fig. 24. RFI versus $H$ He/M for erblum tritide film. A.R. est. = 1.9 before $500^{\circ} \mathrm{C}$ one hour bake. A.R. $=2.2$. 


\section{d. Effect of Storage at Elevated Temperatures}

A number of samples with atomic ratios ranging from 1.8 to 2.0 have been stored at elevated temperatures from a short time after they were placed on the helium measurement apparatus. All showed normal RFI $\left(2-5 \times 10^{-3}\right)$ before they were heated. Upon being heated, each sample emits helium at a much higher rate (x100) for a short time. The tota? gas desorbed during the heat up to the storage temperature is at most a few tenths of a percent of the total amount of helium generated and still trapped in the tritide. Table IV gives the sample temperature, atomic ratio, and figure number for the date.

Table IV

\begin{tabular}{|ccc|}
\hline Figure No. & Atomic Ratio & Storage Temp. \\
\cline { 2 - 3 } 25 & 1.8 & $71^{\circ} \mathrm{C}$ \\
26 & 1.9 & $75^{\circ} \mathrm{C}$ \\
27 & 2.0 & $91^{\circ} \mathrm{C}$ \\
28 & 1.9 & $101^{\circ} \mathrm{C}$ \\
29 & 1.8 & $200^{\circ} \mathrm{C}$ \\
30 & 1.9 & $230^{\circ} \mathrm{C}$ \\
\hline
\end{tabular}

The 5 ample whose dato are displayed in Figure 26 was accidentally heated to about $500^{\circ} \mathrm{C}$ for a few minutes. After that treatment, the 3 He was quite small (off scale below on the figure) for several weeks. Thus, no data are shown for that period. This is similar to the early behavior of the figure 24 sample which had a longer bakeout at $500^{\circ} \mathrm{C}$. There is no obvious large effect of storage temperature al though the tendency is for samples stored at higher temperatures to show somewhat nigher RFI at low He/N concentrations. This trend is apparently reversed at the latest measurements. 


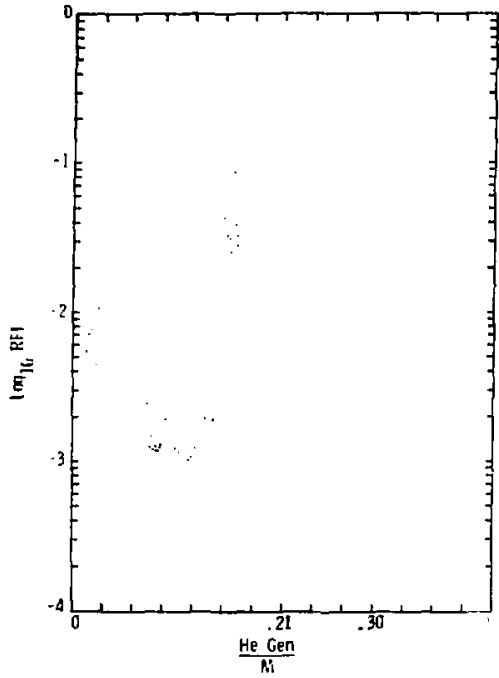

Fig. 25. RFI versus He/M for erbium tritide film. A.R. = l.9, stored at $71^{\circ} \mathrm{C}$.

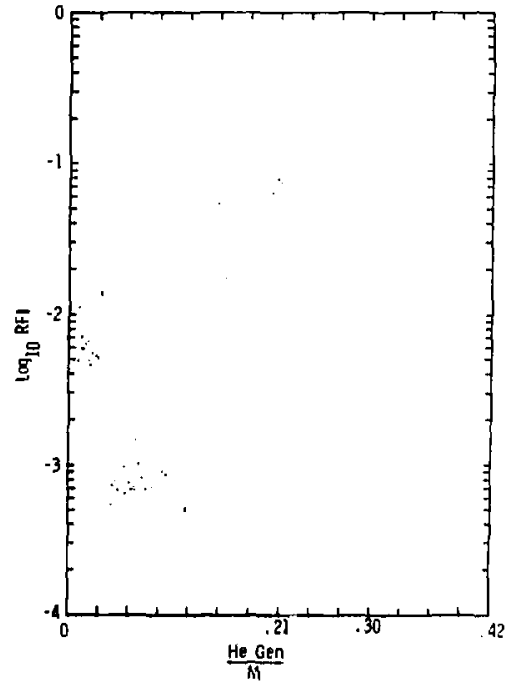

Fig. 26. RFI versus $\mathrm{He} / \mathrm{M}$ for erblum tritide film A.R. = 1.9, stored at $75^{\circ} \mathrm{C}$. 

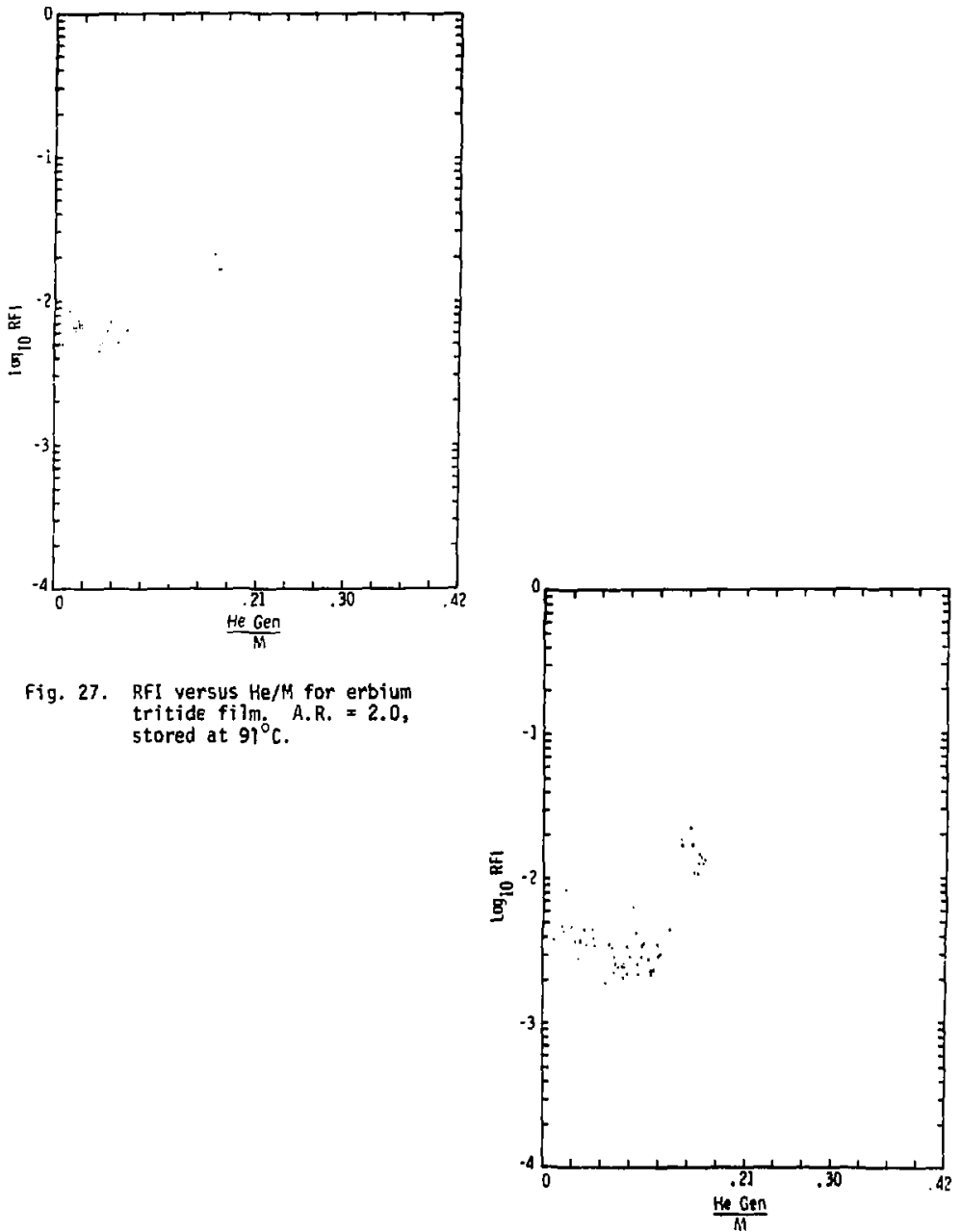

fig. 27. RFI versus $\mathrm{He} / \mathrm{M}$ for erbium tritide film. A.R. $=2.0$, stored at $91^{\circ} \mathrm{C}$.

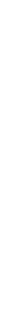




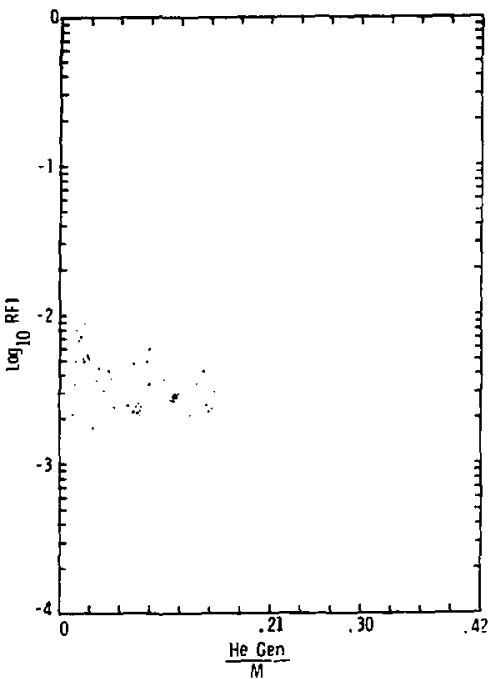

Fig. 29. RFI versus $\mathrm{He} / \mathrm{M}$ for erbium tritide film. A.R. $=1.8$, stared at $200^{\circ} \mathrm{C}$.

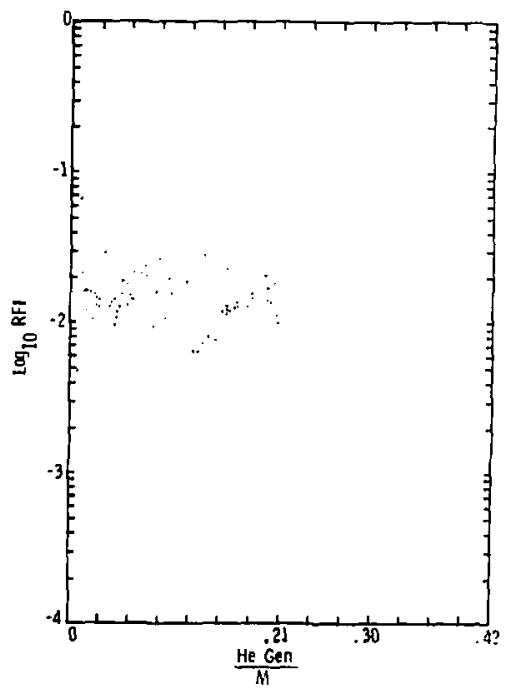

F1g. 30, RFI versus $\mathrm{He} / \mathrm{N}^{\prime}$ for erblum tritide film. $\mathrm{A} . \mathrm{R},=1.9$, 


\section{THERMAL DESORPTION OF ERBIUM TRITIOE}

The description of thermal desorption measurements is given in Reference 19. Erbium tritides of various ages have been run through thermal desorption analysis. The tilemial desorption spectra for samples varying in age from 50 days to 3154 days are st own in Figures 31 - 34. The desorption of Mass 6 and Mass 3 are coplotted on each figure. It is imiediately apparent that the thermal desorption spectra depends upon the age of the sanples. This applies to both the helfum and tritium desorption. It should also be noted that the desorption peak of ${ }^{3}$ He from the youngest sample appears at high temperature, then lower temperature peaks appear as the samples age. The saine applies for the tritium peaks. The 3 He results are similar to those reported by Kass. 20 He did not report on tritium desorption. The oldest samples, figure 34 ,

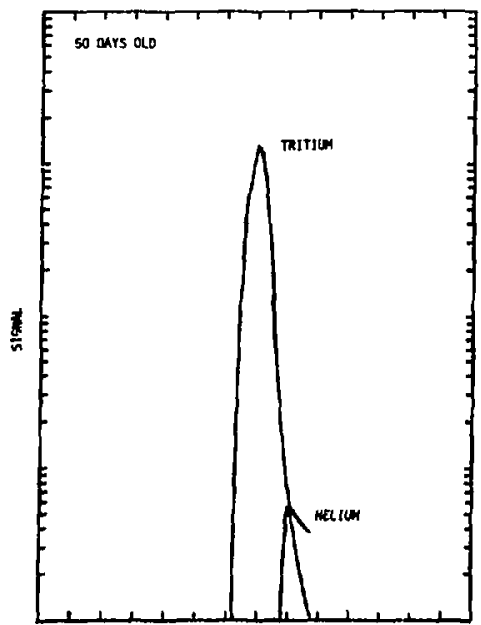

$100200300400500600700100 \times 001000$

Tonchature

F10. 31. Thermal desorption spectra from erisium tritide, A.R. - 1.95; uge -50 davs; $H_{2} / M_{2}=.015$; trittum at mass 6; helfum at mass 3 . Hellum piak corracted for presence of tritlum.

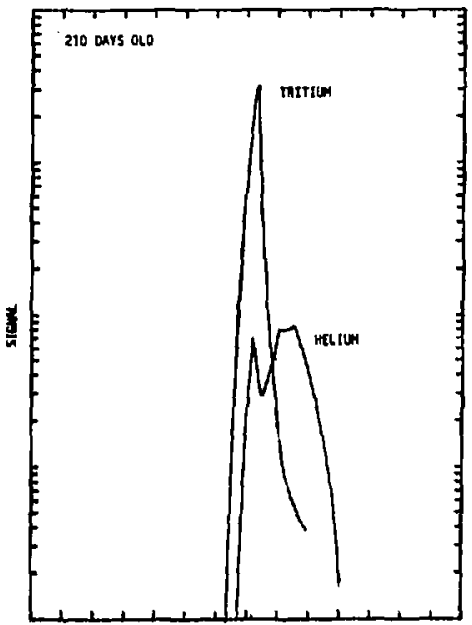

$100200 \times 04005006007001005001000$

Tonature

F10. 32, Thermal desorption spectra from erbiun tritide. $A_{1} R_{1}=1,95 ;$ age -210 days; He/M = .06; trittiun at mass $6 ;$ hillum it mass 3. Hellum penk corrected for presence of tritfum. 


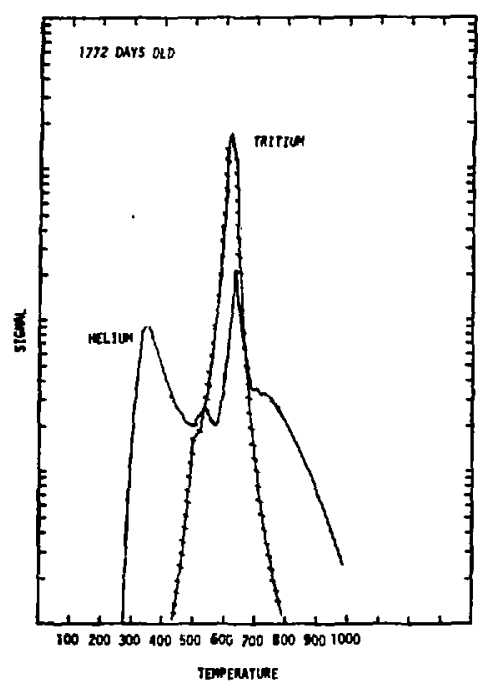

F1g. 33. Thermal desorption spectra from erbium tritide. A. R, = 1.95; age - 1772 days: $\mathrm{He} / \mathrm{IH}=.47$; tritium at mass 6 ; helium at mass 3 . Helium peak corrected for presence of tritium.

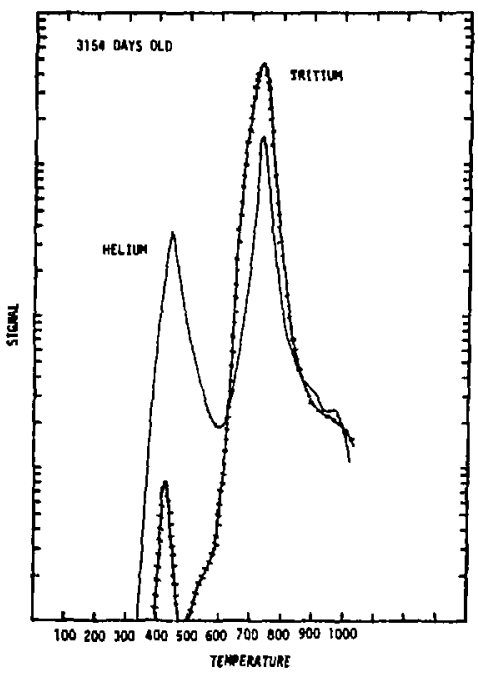

Fig. 34. Thermat desorption spectra from erbium tritide. A.R. $=1.95$; age -3154 days; $\mathrm{He} / \mathrm{M}=.75$; tritilum at mass 6 ; hel lum at mass 3 . Helfum peak corrected for presence of :ritium.

Show a great similarity in desorption spectra to the youngest samples. Figure 31 . Note, however, that the oldest samples show both an eastly desorbed tritium peak and ${ }^{3}$ He peak which is not seen in the youngest desorption samples.

The thermal desorption of implanted tritides similar to those messured by Kass 20 is shown in Figure 35 . In this floure, the tritium, ${ }^{3} \mathrm{He}$, and ${ }^{4} \mathrm{He}$ desorption are coplotted. Note the trittum and He are very simtlar in their desorption behavior and quite different from ${ }^{3}$ He. This is a marked contrast to Kass' data in which the ${ }^{3}$ He and ${ }^{4}$ He in implonts behave very simtlarly to each other. Kass did not report on the tritium desorption from his impiaited samples. 


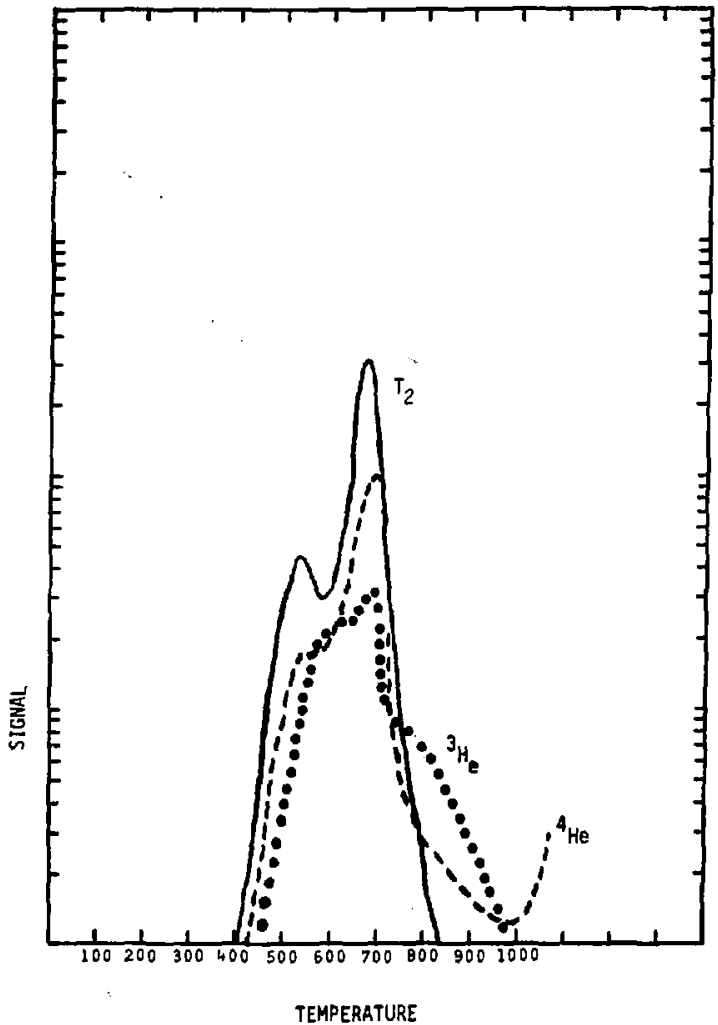

Figure 35, Thermal desorption spectra of hel ium-4 implanted erbium tritide. ${ }^{3} \mathrm{He} / M=.12 ;{ }^{4 e} / M=.19$ helium-3 peak corrected for the presence of tritium. 


\section{DISCUSSION}

It appears that erbium tritide films which have been prepared by differing techniques exhibit much the same early emission of a few tenths of a percent of the helium being generated. The samples in Figures 2-4 were prepared by depositing the films; and without an exposure to air, they were immediately tritided. On the other hand, those samples whose data appear in Figures 5-8 were evaporated, exposed to air for several days, then tritided in a apparatus used specifically for tritiding. All of these samples displayed approximately the same early emission of helium. It also appears that the instantaneous release of hel fum from any given sample is somewhat variable over periods of several days. This variabllity is $\pm 30 \%$ (one standard deviation) about the mean value* which remains nearly constant until a short time before the age $\left(t_{c}\right)$ at which helfum release accelerates to the generation rate. The life of erbium tritide, as far as helium emission is concerned, can be broken into three eras. The first is that which occurs immediately after it is made. The helium is emitted slowly at a rate of a few tenths of a percent of the generation rate $( \pm 30 \%)$. This continues for most of the time to the onset of rapid release $\left(2 / 3\right.$ to $4 / 5$ of $\left.t_{c}\right)$. In the second era, the release fraction begins to increase slowly (again with appreciable variability about the mean) from a few tenths of a percent to a few percent (i.e., a factor of ten) at which point the release fraction suddenly (within hours or days at most) increases to the generation rate or over. This time for ErT 1.9 occurs at about 1150 days. During the last era, the material emits helfum at the generation rate with the same sort of variability we observed earlier. A theory which explains helium entssion from tritides must take into account all three stages of helfum desorption.

In comparing these measuraments to those reported earlier, 13 we find the critical fraction for rapld release $\rho_{c}$ to be somewhat highter $(\approx 0.26$ compared $\approx 0.31$ for the present data). There are two possible explanations for this difference. First, we take the value of $P_{c}$ to be that when RFI exceeds 0.1 . This occurs near the maximum slope in the RFI versus He/M plot and ts easter to measure accurately than the 0.01 value chosen earlfer because the value of 0.01 is exceeded during the second slowlyincreasing RFI stage of the tritides life. The second reason for different value may be because as we make measurements, the overpressure of helfum is taken away; Whereas in the earlfer measurements, the overpressure was al lowed to continually increase during the parfod data were taken. The tftanfum tritide and zirconfum tritide

* This is not an instrumental effect. Although all samples show this effect, they do not show incrasses or decreases the same day. Any given sample shows only smail variations during a 24 -hour pertod. 
samples show behavior similar to that displayed by erbium tritide. That is the onset of rapid release is displaced to higher than expected ${ }^{3}{ }^{3} \mathrm{He} / \mathrm{M}$ ratio for titanium* $(0.4$ reported here versus 0.32 reported in Reference 13). Zirconfum Lritide appears to have an extremely long, low level of helium emission region. ** If this behavior is born out with other samples, it will supplant titanium as the longest lived tritide to onset of rapid helium release.

It is passible that the sample whose data are seen in Figure 9 has a high, early release fraction because the ami-unt of material (erbium and tritium) is greater than initially measured, or that it is in some way different than other similar samples-naybe finer grained, It should be noted that it has not changed its apparent RFI appreciably as of July 1979.

All of the data we have on scandium tritide samples indicate that it does not go through the three life stages of helium emission that erbium tritide (and other tritides we have measured) goes through. Rather, it appears to go through a continual increase from birth until it reaches rapid release when it behaves tike other tritides in this ald-age stage. It is possible that this behavior may be related to the large room temperature solid solubility of tritium in the metal phase. The solid solution and ditritides all exhibit similar behavior (see figures 11 and 12, ditritides; versus Figures 13, 19, and 20, solid solution sampies). These data are in marked contrast to the scandium data report in Reference 13 which shows an initial low-level plateau of helium emission. This disparit data may be due to the measuring technique employed. We pump the gas away whereas the earlier measurements were made in a helium overpressure.

The data indicate that grain boundaries can certainily account for all of the helium seen to be released at low helium-to-metal ratios. In fact, the amount of helium emitted is less than would be predicted from the grain size measurements we have made (see Section B of Results). It should be noted here that if the grain size is smaller than our measurements (possibiy due to poor spacial resolution of the measurement technique), then the amount we underestimate is even greater. It is possible that contaminants, which either trap helium or displace tritium (oxide?), on grain boundaries lead to lower than estimated early release fractions. It is also possible that some grain boundaries are "tighter" than others and thus not able to transmit the gas to the free volume. It is significant that materials which are not constrained, $1, e .$, bulk emits helium at rates closer to those predicted than do fiinis which are mechanically constrained and in compression.

\footnotetext{
*Destructive andysis indicates that the $\mathrm{He} / \mathrm{M}$ values on the plot are about $5 \%$ too high.

** July 1979 data indicate that the helium is still being emitted at a low rate. $\mathrm{He} / M$ is about 0.46 .
} 
Several years ago' we found that as the ditritide phase becomes more saturated with tritium, the critical ratio of $\mathrm{He} / \mathrm{M}$ for the onset of rapid release was reduced significantly. The results from film samples are not as conclusive nor is the displacement of the critical ratio as great, see Tables II and 111 . The evidence for a super-stoichiometric effect on the critical release concentration in f13ms is not conclusive. Possibly the constraint of the substrate influences the material so that the effects observed in bulk, Figure 36.1 are suppressed. It is possible that this effect is due to a micro-fragmentation of the bulk (not observed under SEM, however) which either cannot take place or at least is reduced in films.

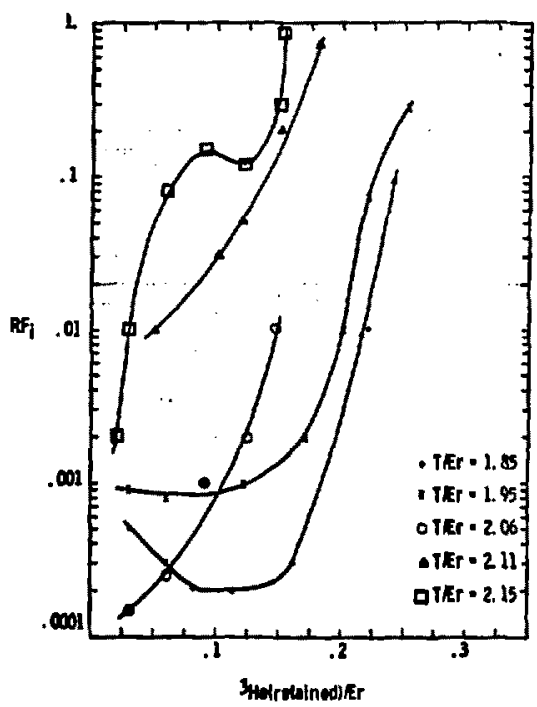

Fig. 36. RFI versus He (retained) to metal ratio for various atomic ratios of erbium tritidas. Data from Reforence 1.

Clearly, films have no "mamory" of having been tritided above an atomic ratio of 2.0. The sample which had beon tritided to 2.2 (partially tritritided) does not show high, eariy helium rolease. The tritritide of orblum is known to release holiun at naarly the ganorotion rate a very short time after it is formed. Thus, if 
the sample with atomic ratio 2.2 had been allowed to retain the tritium, it would have shown high early release. The $500^{\circ} \mathrm{C}$ bakeout destroyed any tritritide and the sampie then behaves 11 ke any other erbium tritide fflm atomic ratio about 1.9 . Imnediately after the bakeout, this sample showed extrenely low helium emisston (RFI $<1 \times 10^{-4}$ ). This is typical behavior of any tritide which is baked out to about $500^{\circ} \mathrm{C}$. The sample whose data are in Figure 26 had a similar bakeout, accidentally, and behaved the same way.

It is not clear that storing erblum tritides at elevated temperatures has any significant impact on their helium emission characteristics. During the initial heating of the samples, those heated to higher temperatures enitted more helium during the heat up and for an extended perted after being heated. The offference in rates gave an apparent activation energy of ielium emission of about $0.1 \mathrm{eV} / \mathrm{atom}$. More recently, this trend has been wiped out. It now appears that a reversal in this trend has taken place, i.e., those samples stored at lower temperatures have higher release fractions (RFI) than those stored at higher temperature (Figures 26 - 301. This reversal does not apply to room temperature stored samples. The effect is minimal in any case, and it may be totally related to such things as the differential expansion between substrate and fllm, or possibly the Impact of gases desorbed from the vacuum storage chamber interacting with a film over an extended period.

The themal desorption spectra from erbium tritides indicate that the helium collected in the youngest samples (50 days old) is most well bound, having a mintmum binding energy of $69 \mathrm{kcal} / \mathrm{mol}$ assuming simple first-order desorption kinetics. The tritium has an apparent binding of $61 \mathrm{kcal} / \mathrm{mol}$. As erbium tritide ages, the helium fills less well-bound sites. For 210 days, the helium fills sites ranging from 62 $\mathrm{kcal} / \mathrm{mol}$ to $72 \mathrm{kcal} / \mathrm{mal}$. Tritium is apparently bound with $62 \mathrm{kcal} / \mathrm{mol}$. From 210 days onward, all samples display a helium desorption peak which is closely tied in energy (temperature) to the desorption of tritium. For 1772-day samples, the helium is bound with $38-68 \mathrm{kcal} / \mathrm{mol}$ while the tritium $1 \mathrm{~s}$ bound with 48 and $55 \mathrm{kcal} / \mathrm{mol}$. Finally, the 3154-day samples display helfum bound with $44 \mathrm{kcal} / \mathrm{mol}$ to $74 \mathrm{kcal} / \mathrm{mol}$ and tritium bound with $43 \mathrm{kcal} / \mathrm{mol}$ to $62 \mathrm{kcal} / \mathrm{mol}$. It is important to keep in mind that the most tightly bound hellum is desorbed from the metal phase and not from the tritide. The large amount of helium desorbed from the trittce as the tritfum is desorbed may be associated with the phase change whtch takes place during desorption. The apparent binding energy of trittum appears to be high (about 15). The reason for this behavior is not known but has been observed in deuteride f1lms of erblum and scandlum. ${ }^{21}$ The helfum-to-metal ratio generated for the samples measured is given in Table $V$. 
Table V

\begin{tabular}{|rl|}
\hline Sample Age & He/M \\
\hline 50 days & .015 \\
210 days & .062 \\
1772 days & .47 \\
3154 days & .75 \\
\hline
\end{tabular}

CONCLUSIONS

From the data reported herein, I believe the following conclusions can be drawn.

1. Early in $71 \mathrm{fe}$, a significant but variable portion of the helium generated at grain boundaries is reieased to the gas phase. This gas accounts for essentialiy all of the early release of hellum from tritides.

2. The early release fraction of helium from unsaturated erblum ditritide is about $0.003 \pm 0.0009$ (1 standard deviation).

3. Scandium tritide does nat exhibit a more or less constant early release fraction as the other tritides observed do.

4. The onset of hellum release at nearly the generation rate from erbium tritide occurs at a helium-to-metal ratio of 0.31 .

5. Elevated storage temperatures up to $230^{\circ} \mathrm{C}$ have 11 ttle or no effect on the early release of hellum from erbium tritide.

6. Erbium tritide films do not show as large an effect of saturation of the ditritide on the concentration (time) for rapid release onset as bulk samples.

7. The first helfum generated in erblum tritide is the most well bound.

8. The presence of helium in erbium tritide reduces the binding energy between erbium and tritium.

9. Because of the apparent high helium-to-metal ratto before the onset of rapid release of hellum, 2 irconium tritide film should be studled more extansivaly. 


\section{REFERENCES}

1. L. C. Beavis and H. J. Kass, J. Vac. Sci. Technol., Vol. 14, "1, pp. 509-513 (1977).

2. E. Bretscher and A. P. French, Phy. Rev. 75, 1154 (1949).

3. J. R. Cost and R. G. Hickman, "Radiation Effects and Tritium Technology and Fusion Reactors," CONF-750989, Vol. 1, pp.234-249 (1976).

4. For example see: J. K. E. Colditz, B. S. Misnheer, and E. Sles, Medica Mundi 20, "3 (1975); or H. H. Barschall, American Scientist 64, Pp.668-673, (1976); or H. Ul lmater, R. Behrisch, and H. H. Barschall, Nuctear Instruments and Methods 145, pp. 1-7 (1977).

5. Metal Hydrides, edited by Mueller, Blackledge, and Libowitz Academic Press, New York 1968.

6. P. M. S. Jones, W. Edmondson, and N. S. McKenna, J. Nucl. Mats. 23, pp.309-312 (1967).

7. A. M. Rodin and V. V. Surenyants, Fiz, Metal Metalloved 10, pp.216-222 $(1960)$.

8. V. P. Vertebnyi, M. F. Vlasov, A. L. Kirilyak, R. A. Zatserkorskii, M. V. Pasechrik, and V. A. Stepaneko, At. Energ. 22, pp.235-237 (1967).

9. A. M. Rodin and V. V. Surenyants, Russ J. Phys. Chem. 45, pp.612-614 (1977).

10. J. R. Cost and R. G. Hickman, J. Vac. Sci. Technol. 12, pp.516-519 (1975).

11. R. 5. Carison (op, cit. 3, Vol, IV, pp.36-52).

12. M. E. Malinowiski and P. R. Cordonado (op. ctt. 3, Vol. IV, pp.53-57).

13. W. G. Perkins, H. J. Kass, and L. C. Beavis (op. cit. 3, Vol. IV, pp.83-97).

14. P. G. Berezhko, Russ J, of Phys, 48, pp.12-14 (1974).

15. W. D. Wilson, C. L, B1sson, and D. E, Amos, J. Mucl. Materials 53, p. 154 (1974).

16. H. T. Weaver and H. J. Camp, Phys, Rev, B 12, p.3054 (1975).

17. H. J. Camp, J. Vac. Sci. Technol. 14, pp.514-517 (1977).

18. E. H. Farnum, "Calculation of Hellum Induced Strain In ErT2 and ScT2," SC-RR-70-753, Sandla Laboratories, Albuquerque, N.M. (1970).

19. L. C. Beavis, "Tharnodesorption of Gases from Various Vacuum Materials," SAND78-1978, Sand1, Laboratortes, Albuquerque, H.H. (1979).

20. H. J. Kass, J. Vac. Sc1. Technol, 14, pp.518-522 (1977).

21. D. F. Cowgil), Private comunication (Jan. 1979), 